\title{
The role of the implementation of policies for the prevention of exposure to Radon in Brazil-a strategy for controlling the risk of developing lung cancer
}

\author{
Aline da Rocha Lino, Carina Meira Abrahão, Marcus Paulo Fernandes Amarante and Marcelo Rocha de Sousa Cruz
}

Rua Martiniano de Carvalho, 965, Bela Vista, São Paul-SP, Brazil, CEP 01321-001

Correspondence to: Marcelo Rocha de Sousa Cruz. Email: marcelo.cruz.md@gmail.com

\begin{abstract}
Lung cancer is the leading cause of cancer death in the United States and other industrialised countries. The most important risk factor is active smoking. However, given the increased incidence of lung cancer in non-smokers, it is necessary to improve knowledge regarding other risk factors. Radon $(\mathrm{Rn})$ is a noble gas and is the most important natural source of human exposure to ionizing radiation. Exposure to high levels of this radioactive gas is related to an increased risk of developing lung cancer. The objective of this work is to highlight the importance of measuring indoor concentration of this gas and identify which steps should be taken for achieving radiological protection.

A survey was conducted on the websites of the National Health Surveillance Agency (ANVISA), LAMIN (Mineral Analysis Laboratory), CPRM (Geological Survey of Brazil), Ministry of Health and PubMed. Using the words 'radon', 'lung', 'cancer', and PubMed®, 1,371 results were obtained; when using the words 'radon', 'lung', 'cancer', and with 'Brazil' or 'Brazilians', only six results were obtained. We emphasise that lung cancer is a major public health problem and the exposure to $\mathrm{Rn}$ indoors should be considered as a risk factor for lung cancer in non-smokers. Buildings or houses with high concentrations of Rn should be identified. However, currently in Brazil-a country with great potential for mineral extraction-there are no specific regulated recommendations to control indoor exposure to Rn.
\end{abstract}

Keywords: cancer, radon, lung

Published: 14/09/2015

Received: $10 / 04 / 2015$

ecancer 2015, 9:572 DOI: 10.3332/ecancer.2015.572

Copyright: (c) the authors; licensee ecancermedicalscience. This is an Open Access article distributed under the terms of the Creative Commons Attribution License (http://creativecommons.org/licenses/by/3.0), which permits unrestricted use, distribution, and reproduction in any medium, provided the original work is properly cited. 


\section{Introduction}

Lung cancer represents the main cause of death from cancer throughout the world. The mean cumulative total survival rate at five years varies between $13 \%$ and $21 \%$ in developed countries and $7 \%$ and $10 \%$ in developing countries [1]. The global estimate gave an incidence of 1.82 million new cases of lung cancer for the year 2012. In Brazil, it was responsible for 22,424 deaths in 2011 , and 27,330 new cases were expected for the year 2014 [2].

Though its main risk factor continues to be the consumption of tobacco products [3], there has been an increase in the number of cases in non-smoker patients. For this reason, it has become necessary to better understand other risk factors. Among these are passive or second-hand smoking, inflammatory lung disease (such as fibrosis of the lung and chronic obstructive pulmonary disease), exposure to Radon (Rn), asbestos, air pollution and smoke from burning wood [4]. The death rates from lung cancer are declining in developed countries, where tobacco consumption has declined in the last decades. In contrast, the rates of lung cancer and mortality are increasing in developing countries, including many countries of Latin America [1].

$\mathrm{Rn}$ has been recognized as the second most common cause of lung cancer in 2005 by the United States Environmental Protection Agency (EPA) [5]. In 2009, the World Health Organization (WHO) in conjunction with EPA launched a first global call-to-action on cancer risk from radon in homes [6]. Thus, it is of fundamental importance to disseminate knowledge about Rn. In Brazil very little information has been released or discussed regarding exposure and prevention of exposure to $\mathrm{Rn}$. This article provides a description of the data found regarding $\mathrm{Rn}$, when and where human contact with the gas occurs, and the policies for prevention that have been implemented in the country.

$\mathrm{Rn}$ is an inert natural gas, and is a product of the decay of Radium-226 (Ra-226) [7]. Its concentrations are directly related to the type of geologic formation of a specific region, given that the types of rock that compose these soils can contain smaller or larger quantities of the minerals Uranium (Ur), Thorium (Th), and Radium (Ra), the natural producers of Rn-222 [8].

This gas can escape through fissures or be transported from the subsoil to the surface by means of pipes, holes, and groundwater deposits, and thus become a source of exposure for the people who reside in or frequent these areas [8, 9].

The release of $\mathrm{Rn}$ from rock and soil is controlled by mineralogical factors such as solubility and imperfections in the crystalline structure, also specific surface of the minerals that contain uranium. The probability of Rn escaping from the mineral is much greater at the edges of the crystals. The soils generally release more $\mathrm{Rn}$ than the rocks, as their component elements are more easily separated [10].

Most exposure to Rn occurs in enclosed environments such as tunnels, caves, mines, houses, and other dwellings. An important form of exposure of individuals inside residences is by inhalation of the Rn isotopes and the products of their decay with a short half-life. It has been proven that high concentrations of $\mathrm{Rn}$ within buildings are the result of its release into the atmosphere from the soil through convection [11]. Measures for reducing exposure to Rn include improved ventilation, remediation of Rn, and new construction techniques that reduce the risk of exposure $[12,13]$. A variety of $\mathrm{Rn}$ mitigation strategies are being used, with different efficacy rates. The ideal strategy depends on the probable source or cause, characteristics of the construction, soil, and climate [13].

In its gaseous state, $\mathrm{Rn}$ is colorless, odorless, and tasteless and its particles can be inhaled from the air, and thus penetrate a short distance into the bronchial epithelium, where it can cause biological damage such as mutations to DNA base pairs and chromosomal breakages [13]. $\mathrm{Rn}$ is the most important natural source of human exposure to ionizing radiation [9]. Radioactivity due to Rn accounts for $54 \%$ of the radiation to which we are exposed daily [14].

Epidemiological studies have demonstrated the synergistic effect between Rn and smoking tobacco [16]. It has been demonstrated that with the same exposure to $\mathrm{Rn}$ and its decay products, the risk of lung cancer among smokers is greater than that of non-smokers [17].

\section{Methods}

An extensive survey was conducted between 30 October 2014 and 27 June 2015 using the word 'radon' on the websites of the following Brazilian Federal Authorities: National Agency of Health Surveillance (from Portuguese ANVISA), Mineral Analysis Laboratory (from Portuguese LAMIN), Mineral Resources Research Company (from Portuguese CPRM), and Ministry of Health. We have also contacted the ANVISA authorities for further information about national health policies on $\mathrm{Rn}$ level control and exposure mitigation. 
A PubMed search was also conducted of the principal data published domestically and internationally on the relationship between Rn and lung cancer. A descriptive analysis of the data collected was performed.

\section{Results and Discussion}

When using the words 'radon', 'lung', 'cancer', and PubMed, 1,371 results were obtained; by adding the word 'Brazil', only six results were obtained. Of these, two articles dealt with exposure to Rn in coal mines, two were studies conducted outside the country which mentioned Brazil, and the remaining two articles were the only that dealt with studies of Rn in the Brazilian population [18, 19].

Lung cancer in non-smoking patients shows differences in the clinical, pathological, and molecular aspects in comparison to lung cancer in smokers [20]. The principal factors associated with neoplasia of the lung in non-smokers include exposure to known and suspected carcinogenic agents, including Rn, passive smoking, and other air pollutants [21].

The Environmental Protection Agency of the United States (EPA) estimates that Rn is the principal cause of lung cancer in non-smokers, and may be responsible for nearly 21,000 deaths from lung cancer per year [14]. A Brazilian study conducted in the city of Poços de Caldas, located in an area with high levels of natural radiation, showed a lifetime increase of $20 \%$ in deaths from lung cancer because of exposure to Rn. It was also estimated that $16 \%$ of all of the deaths from lung cancer in Poços de Caldas could be attributed to exposure to Rn [18].

Besides EPA and WHO statements, Rn is also classified as a Class I carcinogen by the International Agency for Research on Cancer (IARC) [22]. Indoor Rn exposure seems to be a risk factor for all histological types of lung cancer. In individuals diagnosed at a younger age, a higher concentration of residential Rn was identified [23]. According to the International Commission on Radiological Protection (ICRP), the management of exposure to $\mathrm{Rn}$ is principally based on the application of the principle of optimization below an appropriate reference level of natural radiation (NR). The ICRP recommends 10 millisieverts (mSv) per year as an acceptable dose of radiation absorbed through exposure to $\mathrm{Rn}$. The highest recommended reference level for radiation activity in residences is 300 Bequerels per cubic meter (Bq/ $\mathrm{m}^{3}$ - $\mathrm{as}$ an average yearly concentration). The same level is recommended for mixed-use buildings. A specific gradual approach is recommended in work environments: 1) application of the same NR as for dwellings (as long as the corresponding dose is less than $10 \mathrm{mSv} / \mathrm{year}$, mainly because of exposure time); 2) application of the NR of $10 \mathrm{mSv} / \mathrm{year}$, taking the actual conditions of exposure into account; 3) application of the relevant requirements for occupational exposure when, despite the use of possible measures, exposure remains above $10 \mathrm{mSv} / \mathrm{year}$ (quantitative criteria), or when the work activity is on a list of occupations with a risk of exposure to Rn (qualitative criteria) [22]. While the action level in the USA is $148 \mathrm{~Bq} / \mathrm{m}^{3}$ and in Europe it is $200 \mathrm{~Bq} / \mathrm{m}^{3}$ for new homes, WHO recently proposed a reduction in the exposure levels to below $100 \mathrm{~Bq} / \mathrm{m}^{3}$ [6].

Three analyses comparing data on individual exposure, including 13 European, 7 North American, and 2 Chinese studies, showed that Rn is a carcinogenic agent in the general population in concentrations found in typical homes, and that there is a linear relationship between the dose and response curves with no evidence of a plateau, as well as evidence of an increased risk even with concentrations below $200 \mathrm{~Bq} / \mathrm{m}^{3}$ [24, 25]. In contrast, a meta-analysis of 60 publications showed a non-linear association of the dose and response between exposure to environmental $\mathrm{Rn}$ and the risk of lung cancer. This increased risk is particularly evident when the cumulative exposure to Rn is well above the recommended concentration limit for a long period of time [26].

The 'radon manual' is a key product of the 'International WHO Radon Project' launched in 2005. The manual focuses on exposure to residential $\mathrm{Rn}$ from a public health perspective and provides detailed recommendations for the reduction of health risks arising from this gas and actions to prevent and mitigate exposure to the same. This publication is intended for countries that seek to develop their national programmes or extend such activities, as well as parties interested in control, such as the construction industries and professionals [6]. It is important to note that should there be an intervention at a location, then a considerable reduction in the concentration of Rn is required, not only reduction but what is needed here is to achieve a level of exposure which is below the lowest limit of the recommended range.

In Brazil, according to the National Agency of Health Surveillance (ANVISA) regulations and legislation currently only cover workers who are directly exposed to large concentrations of the gas such as those in mining, for example. Thus, information on Rn concentrations within buildings, offices, houses and construction materials are not available (personal e-mail received on 19 December 2014). 
Marques et al (2006) identified a relatively high concentration of $\mathrm{Rn}$ in the water, residences, soil, and caves in a Brazilian region, which in some cases reached levels above the maximum limits recommended internationally. The authors suggest that intervention activities be implemented for the dissipation of $\mathrm{Rn}$ both in residences and during the collection of water for human consumption [8].

A study conducted in Canada demonstrated that a public health strategy based on testing and mitigation could theoretically prevent $11 \%$ of deaths from lung cancer attributable to Rn each year, if in all of the homes tested with levels above the current Canadian standard of $200 \mathrm{~Bq} / \mathrm{m}^{3}$ were reduced to minimum levels. If the WHO standard of $100 \mathrm{~Bq} / \mathrm{m}^{3}$ were used, $28 \%$ of the deaths from lung cancer attributable to Rn could be avoided annually [23]. A Swedish study showed that nearly $25-30 \%$ of the cases of lung cancer attributable to exposure to Rn could be avoided if all of the residential concentrations of Rn above $200 \mathrm{~Bq} / \mathrm{m}^{3}$ were reduced to $140 \mathrm{~Bq} / \mathrm{m}^{3}$; while if all of the exposures above $200 \mathrm{~Bq} / \mathrm{m}^{3}$ were reduced to $100 \mathrm{~Bq} / \mathrm{m}^{3}$, nearly $35-40 \%$ of these cases could be avoided [12]. Hunter et al (2015) demonstrated that the mitigation of Rn can have a substantial impact on the risk of lung cancer, even for persons in their sixth decade of life and beyond; in smokers, former smokers, and people who have never smoked, reducing by more than a third the risk of lung cancer induced by Rn [27].

Another study conducted in the American state of Minnesota to assess the effectiveness of soil ventilation systems for 140 randomly selected clients of six professional mitigators found an average concentration of Rn of $280 \mathrm{~Bq}(10.3 \mathrm{pCi})$ before mitigation. The average $\mathrm{Rn}$ following mitigation in the homes was of $30 \mathrm{~Bq} / \mathrm{m}^{3}$, with an average reduction of more than $90 \%$. Even years after the mitigation, $97 \%$ of these homes had concentrations below the action level of $150 \mathrm{~Bq} / \mathrm{m}^{3}$ for the United States Environmental Protection Agency [28].

Under Brazilian national regulations, subsection 6.1.3.2 of Regulation CNEN-NN3.01 establishes that in situations of chronic exposure, when relevant action levels have been exceeded, as calculated based on the intervention levels established or approved by the CNEN (National Nuclear Energy Commission), mediatory action must be taken'. An annual dose of 10 mSv must be used as a general reference value for an intervention action in situations of chronic exposure. The CNEN considers intervention to be justified whenever the existing dose is greater than $50 \mathrm{mSv}$ per year [29].

The United States Office of the Surgeon General and EPA recommend that tests be performed in all homes to detect the presence of Rn [30].

As for policies for the prevention of lung cancer, an American study which reviewed 65 control programmes showed that 27 (42\%) included terminology specific to $\mathrm{Rn}$, and mentioned the need to improve understanding of $\mathrm{Rn}$ as a risk factor. Also included were tests for $\mathrm{Rn}$ in homes $(n=21)$, remediation activities $(n=11)$, support for Rn policies $(n=13)$, and assessment of policies $(n=1)$ [30]. As is the trend in Europe and North America, interior Rn exposure is increasingly recognized in Brazil as an agent that contributes to the risk of lung cancer. Scattered regional surveys conducted in Brazil have shown that the Rn problem may exist in certain areas, but little is known about its possibilities in full extent [31].

\section{Conclusions}

Based on all of the data examined, our conclusion is that $\mathrm{Rn}$ must be considered as a risk factor for the development of lung cancer, and major measures must be taken in order to reduce this risk. We recommend that the Ministry of Health in Brazil, along with the responsible agencies, initiate policies for the investigation and mapping of locations in terms of the risk of exposure from this gas. The identification of the areas with high concentrations of exposure to $\mathrm{Rn}$ is considered to be of fundamental importance. Directives for the reduction of risk of exposure to this gas, as well as incentives for the construction of buildings to resist the gas and improvements to their ventilation systems are important measures. It is also necessary to initiate policies for increasing awareness and educating the population about what $\mathrm{Rn}$ is, its risks, and how the population can avoid it.

\section{List of abbreviations}

ANVISA National Health Agency of Surveillance (Brazil)

CNEN National Nuclear Energy Commission (Brazil)

EPA Environmental Protection Agency (USA) 
IARC International Agency for Research on Cancer

ICRP International Commission on Radiological Protection

LAMIN Mineral Analysis Laboratory (Brazil)

WHO World Health Organisation

Rn Radon

\section{Conflicts of Interest}

This study does not present any personal or economic conflicts of interest.

\section{References}

1. Jemal A, Bray F and Ferlay J (2011) Global Cancer Statistics CA Cancer J Clin 61(2) 69-90 DOI: 10.3322/caac.20107 PMID: $\underline{21296855}$

2. Intistuto Nacional do Câncer INCA - Brazil. Available at www.inca.gov.br/estimativa/2014 (accessed 10 April 2015)

3. General S, States U, and Services H (2000) Executive Summary 1-20

4. Manuscript A NIH Public Access (2013) 32(4) 1-61 Lung DOI: 10.1016/i.ccm.2011.09.001

5. Residential Radon and Risk of Lung Cancer: A Combined Analysis of 7 North American Case-control Studies Epidemiology, 2005 March; 16(2) 137-45 available at http://www.epa.gov/radon/pdfs/na rn_pooling.pdf (accessed 10 April 2015)

6. WHO Handobook on Indoor Radon. A Public Health Perspective. available at http://www.who.int/ionizing radiation/env/radon/en/ (accessed 10 April 2015)

7. Juste B, Ortiz J, Verdú G and Martorell S Air radon concentration decrease in a waste water treatment plant Radiat Prot Dosimetry 2015 DOI: 10.1093/rpd/ PMID: 25971342

8. Marques AL, Geraldo LP and Santos W (2006) Níveis de radioatividade natural decorrente do radônio no complex rochoso da Serra de São Vicente SP Radiol Bras 39(3) 215-18 DOI: 10.1590/S0100-39842006000300012

9. Krewski $\mathrm{D}$ et al (2006) A combined analysis of North American case-control studies of residential radon and lung cancer J Toxicol Environ Health A 69(7) 533-97 DOI: 10.1080/15287390500260945 PMID: 16608828

10. Federal U, Rio DO and Do G (2011) Concentrações de radônio nas águas subterrâneas, rochas e solos de porto alegre - rs subterrâneas, rochas e solos de porto alegre, RS Mostrar registro completo

11. Fernandes HM, Rio MAP and Franklin MR (2004) Impactos Radiológicos da Indústria do Fosfato Série Estud Doc 56(ISSN 0103-6319)

12. Axelsson G, Andersson EM and Barregard $L$ (2015) Lung cancer risk from radon exposure in dwellings in Sweden: how many cases can be prevented if radon levels are lowered? Cancer Causes Control 26(4) 541-7 DOI: 10.1007/s10552-015-0531-6 PMID: 25677843 PMCID: $\underline{4365178}$

13. Radon and lung cancer: Assessing and mitigating the risk Cleveland Clin J Med. Available at http://www.ccjm.org/past-issues/ past-issue-single-view/radon-and-lung-cancer-assessing-and-mitigating-the-risk/12c649e4019f1cc1c60e0effbd859ddb.html?tx ttnews\%5BsViewPointer\%5D=1 accessed 13 June 2015

14. US EPA OIED Radon Health Risks. Available at http://www.epa.gov/radon/healthrisks.html (accessed 10 April 2015) 
15. Geraldo LP et al (2005) Medidas dos níveis de radônio em diferentes tipos de ambientes internos na região da baixada santista, SP* 38(6) 283-6

16. Darby $S$ et al (2005) Radon in homes and risk of lung cancer: collaborative analysis of individual data from 13 European case- control studies BMJ 330(7485) 223 DOI: $10.1136 / \mathrm{bmj} .38308 .477650 .63$ PMCID: $\underline{546066}$

17. Darby $S$ et al (2010) 13 epidemiologic studies in Europe Residential radon and lung cancer-detailed results of a collaborative analysis of individual data on 7148 persons with lung cancer and 14208 persons without lung cancer from 13 epidemiologic studies in Europe Scand J Work Environ Health 32(1) 1-83

18. Veiga LHS et al (2003) Preliminary indoor radon risk assessment at the Poços de Caldas Plateau, MG-Brazil J Environ Radioact 70(3) 161-76 DOI: 10.1016/S0265-931X(03)00101-2 PMID: $\underline{12957547}$

19. Da Silva NC and Bossew $\mathrm{P}$ (2014) The planned Brazilian indoor radon survey-concepts and particular challenges. Radiat Prot Dosimetry 162(1-2) 105-9 DOI: 10.1093/rpd/ncu239 PMID: 25157199

20. Samet JM et al (2009) Lung cancer in never smokers: clinical epidemiology and environmental risk factors Clin Cancer Res 15(18) 5626-45 DOI: 10.1158/1078-0432.CCR-09-0376 PMID: 19755391 PMCID: $\underline{3170525}$

21. Thun MJ and Rudin CM (2011) Lung cancer in never smokers: clinical epidemiology and environmental risk factors 15(18) 5626-45 LUNG DOI: 10.1158/1078-0432.CCR-09-0376

22. Radiological Protection against Radon Exposure http://www.icrp.org/docs/Radiological Protection against Radon Exposure consultation.pdf accessed 13 June 2015

23. Parker L and Craft AW (1996) Radon and childhood cancers Eur J Cancer 32A(2) 201-4 DOI: 10.1016/0959-8049(96)00021-4 PMID: 8664027

24. Torres-Durán M et al (2014) Residential radon and lung cancer in never smokers. A systematic review Cancer Lett 345(1) 21-6 DOI: $10.1016 /$ j.canlet.2013.12.010

25. Vogiannis E G and Nikolopoulos D (2015) Radon sources and associated risk in terms of exposure and dose Front Public Health 2207 DOI: 10.3389/fpubh.2014.00207 PMID: 25601905 PMCID: 4283434

26. Duan $\mathrm{P}$ et al (2015) Non linear dose-response relationship between radon exposure and the risk of lung cancer: evidence from a meta-analysis of published observational studies Eur J Cancer Prev 24(4) 267-7 DOI: 10.1097/CEJ.0000000000000066

27. Hunter $\mathrm{N}$ et al (2015) Calculation of lifetime lung cancer risks associated with radon exposure, based on various models and exposure scenarios J Radiol Prot 35(3) 539-55 DOI: 10.1088/0952-4746/35/3/539 PMID: 26083042

28. Steck DJ (2012) The Effectiveness of Mitigation for Reducing Radon Risk in Single-Family Minnesota Homes Health Phys 103(3) 241-8 DOI: $\underline{10.1097 / H P .0 b 013 e 318250 c 37 a}$ PMID: $\underline{22850228}$

29. Posição regulatória 3.01/007 Níveis de Intervenção e de Ação para Exposição Crônica. Available at http://www.cnen.gov.br/segurancal normas/pdf/pr301 07.pdf accessed 13 June 2015

30. National Health Advisory on Radon. Available at http://wayback.archive-it.org/3926/20140421162524/http:/www.surgeongeneral.gov/ news/2005/01/sg01132005.html\#skip (accessed 13 June 2015)

31. Neri A, Stewart SL and Angell W (2013) Radon Control Activities for Lung Cancer Prevention in National Comprehensive Cancer Control Program Plans, 2005-2011 Prev Chronic Dis 10 E132120337 DOI: 10.5888/pcd10.120337 